\title{
Aggregation in the Anionic Polymerization of Hexamethylcyclotrisiloxane with Lithium Counterion
}

\author{
Dedicated to the Memory of the late Professor Ichiro Sakurada
}

\author{
Lech WILCZEK* and Joseph P. KENNEDY** \\ Institute of Polymer Science, The University of Akron, \\ Akron, Ohio 44325, U.S.A.
}

(Received November 14, 1986)

\begin{abstract}
The kinetics of the polymerization of hexamethylcyclotrisiloxane $\mathrm{D}_{3}$ initiated by lithium 2,4,4-trimethyl-1-pentanolate $\left(\mathrm{CH}_{3}\right)_{3} \mathrm{CCH}_{2} \mathrm{CH}\left(\mathrm{CH}_{3}\right) \mathrm{CH}_{2} \mathrm{OLi}$ in THF solution in the range $0-60^{\circ} \mathrm{C}$ has been investigated. Polymerization was essentially first order in respect to monomer. Independent of the temperature in the range from 0 to $60^{\circ} \mathrm{C}$, the external order of the rate with respect to initiator changed from 0.25 to 0.33 by changing the initiator concentration from $10^{-1} \mathrm{M}$ to $10^{-3} \mathrm{M}$. This change indicates a change in the degree of aggregation from 4 to 3 of the propagation-active siloxanolate groups. The presence of aggregates and the change in their degree of aggregation from 4 to 3 has been independently and quantitatively confirmed by viscometry carried out before and after quenching the living $\mathrm{D}_{3}$ polymerization by $\mathrm{Me}_{n-4} \mathrm{SiCl}_{n}(n=1-4)$ and $\mathrm{Cl}_{2} \mathrm{SiMeCH}_{2} \mathrm{CH}_{2} \mathrm{MeSiCl}_{2}$. Evidently most of the siloxanolate end groups are organized into. aggregates whose size is controlled by the concentrations of the siloxanolate groups in the range from $10^{-3}$ to $10^{-1} \mathrm{M}$ but insignificantly by the temperature from 0 to $60^{\circ} \mathrm{C}$. Propagation is due to a relatively small proportion of active unaggregated ion pairs.
\end{abstract}

KEY WORDS Living Polymerization / Anionic Polymerization / Hexamethylcyclotrisiloxane / Polydimethylsiloxane / Lithium Alcoholate / Polymerization Kinetics / Aggregation of the Growing End Groups /

In the course of our fundamental investigations on the synthesis of various poly(dimethylsiloxane- $b$-isobutylene- $b$-dimethylsiloxane) (PDMS- $b$-PIB- $b$-PDMS) block copolymers carried out by the anionic blocking of $\mathrm{D}_{3}$ from PIBs capped by $-\mathrm{CH}_{2} \mathrm{OLi}$ groups, ${ }^{1}$ we have discovered evidence for the existence of strong silanolate group aggregation. Thus di-living LiOPDMS- $b$-PIB- $b$ PDMSOLi triblocks yielded gels under certain well-defined conditions $(20 \% \mathrm{v} / \mathrm{v}$ triblock, $\bar{M}_{n} \sim 20,000,2 \times 10^{-2} \mathrm{M}$ active end, tetrahydrofuran (THF), $26^{\circ} \mathrm{C}$ ); however, these gels could be readily converted into relatively low viscosity solutions $\left(\eta_{\mathrm{sp}} \sim 9.5\right)$ by the addition of $\mathrm{Me}_{3} \mathrm{SiCl}$. Evidently the gels comprised living triblock aggregates containing more than two $-\mathrm{SiMe}_{2} \mathrm{OLi}$ ion pairs per aggregate. Similar aggregates have been described to form during the living polymerization of ethylene oxide. ${ }^{2,3}$ Prompted by these observations and in order to deepen our understanding of the mechanism of anionic cyclic siloxane polymerization we decided to explore these effects in detail. These investigations have led to a quantitative understanding of the effect of $-\mathrm{SiMe}_{2} \mathrm{OLi}$ aggregates

* Visiting Scientist: Permanent address: Centre of Molecular and Macromolecular Studies, Polish Academy of Sciences, Boczna 5, 90-362, Lodz, Poland.

** Author to whom correspondence should be addressed 
on the polymerization of $\mathrm{D}_{3}$.

Association of living groups frequently occur in anionic polymerizations of vinyl or diene monomers and strongly affect the kinetics and molecular weight profile of the systems. $^{2-6}$ While kinetic investigations of anionic polymerization of cyclic siloxanes also indicate the presence of aggregations, a quantitative description of these phenomena is difficult on account of simultaneous redistribution reactions, possible ion pair dissociations, etc. ${ }^{7-9}$. According to the current view the propagating species in anionic cyclic siloxane polymerization are most likely unaggregated ion pairs of siloxanolates with alkali metal cations ${ }^{7-9}$ since the living systems do not show measurable electrical conductivity. ${ }^{10}$ Participation of free ions in propagation has also been considered by some authors since the rate of cyclosiloxane polymerizations in the presence of various counter ions generally follows the square-root of siloxanolate concentration. ${ }^{7,11}$

The purpose of the present study was to elucidate the influence of aggregation on the anionic living polymerization of $\mathrm{D}_{3}$ initiated by $\left(\mathrm{CH}_{3}\right)_{3} \mathrm{CCH}_{2} \mathrm{CH}\left(\mathrm{CH}_{3}\right) \mathrm{CH}_{2} \mathrm{OLi}$ in THF solution. This specific (model) system is superior to other systems used so far because in it complex redistribution and ion-pair dissociation effects are minimized. Specifically, among all the alkali metal siloxanolates studied the lithium siloxanolate exhibits the highest selectivity toward the siloxane bond and shows the highest aggregation (lowest dissociation) tendency. ${ }^{7,10,12}$ The $\left(\mathrm{CH}_{3}\right)_{3} \mathrm{C}$ $\mathrm{CH}_{2} \mathrm{CH}\left(\mathrm{CH}_{3}\right) \mathrm{CH}_{2} \mathrm{OLi} / \mathrm{D}_{3}$ combination was of particular interest to us because it is a model system for our research directed toward the synthesis of polyisobutylene PIB/ polydimethylsiloxane PDMS block copolymers. ${ }^{1}$

\section{EXPERIMENTAL}

\section{Materials}

The source and purification of most of the chemicals used. have been described. ${ }^{1} \mathrm{MeSiCl}_{3}$ and $\mathrm{SiCl}_{4}$ (Petrarch Inc.) were purified as described for $\mathrm{Me}_{3} \mathrm{SiCl}$ and $\mathrm{Me}_{2} \mathrm{SiCl}_{2} \cdot{ }^{1}$ 1,4Dimethyl-1,1,4,4-tetrachloro-1,2-disilelthylene (Petrarch Inc.) was purified by evaporation of volatiles under high vacuum for $30 \mathrm{~min}$. The chlorosilane solutions in THF $(\sim 30 \% \mathrm{v} / \mathrm{v})$ were prepared in vials with a Rotaflo stopcock under $\mathrm{N}_{2}$.

\section{Procedures}

The techniques used for kinetic studies of $D_{3}$ polymerization and GC analysis have been described. $^{1}$

\section{Viscometric Measurements}

Viscometric measurements of the polymerization systems were done by the use of vacuum viscometers ( $\sim 30 \mathrm{ml}$ capacity), similar to those used by others. ${ }^{13}$ The viscometers were equipped with a $1 \mathrm{~mm}$ i.d. capillary and Rotaflo stopcock. The viscometer was evacuated for $3-4 \mathrm{~h}$ under high vacuum, twice flamed and filled with 4-7 ml THF and 2.5$4.5 \mathrm{ml} \mathrm{D}_{3}$ solution in THF $(\sim 1.0 \mathrm{M})$ using syringes under $\mathrm{N}_{2}$. Reactions were initiated by the addition of $0.05-1.5 \mathrm{ml}$ lithium 2,4,4trimethyl-1-pentanolate $\left(\mathrm{CH}_{3}\right) \mathrm{CCH}_{2} \mathrm{CH}$ $\left(\mathrm{CH}_{3}\right) \mathrm{CH}_{2} \mathrm{OLi}$ (TMP-OLi) solution in THF $\sim 0.4 \mathrm{M}$ ) with a syringe under $\mathrm{N}_{2}$. At suitable time intervals the specific viscosities (flow times) of the entire charges were determined at $23^{\circ} \mathrm{C}$. After the viscosities of the charges became stabilized $(4-16 \mathrm{~h})$, i.e., after complete $\mathrm{D}_{3}$ polymerization ascertained by GC analysis of a sample withdrawn by a syringe under $\mathrm{N}_{2}$, the charges were treated with the appropriate chlorosilane $\left(\mathrm{Cl}_{n} \mathrm{SiMe}_{4-n}\right.$, where $n=1,2,3,4$ or $\mathrm{Cl}_{2} \mathrm{SiMeCH}_{2} \mathrm{CH}_{2} \mathrm{MeSi}-$ $\mathrm{Cl}_{2}$ ) solutions in THF $(30 \% \mathrm{v} / \mathrm{v})$. Equimolar amounts of $\mathrm{ClSi}-$ relative to the $\sim \mathrm{OLi}$ groups were used for this "killing" step. The 
specific viscosities of the charges were then again determined (flow time measurement after they became stabilized, $0.5-40 \mathrm{~h}$ ).

\section{RESULTS AND DISCUSSION}

We set out to investigate aggregation phenomena in the $\mathrm{D}_{3} / \mathrm{TMP}-\mathrm{OLi} / \mathrm{THF}$ system by two independent self-reinforcing techniques: kinetic studies and viscometry before and after quenching living $\mathrm{D}_{3}$ polymerizations.

\section{A) Kinetic Studies}

We have documented that initiation of $\mathrm{D}_{3}$ polymerization by the use of TMP-OLi at $\sim 10^{-2} \mathrm{M}$ in THF at $26^{\circ} \mathrm{C}$ is rapid and quantitative. ${ }^{1}$ We have now extended the range of initiator concentration from $10^{-3}$ to $10^{-1} \mathrm{M}$ and the temperature range from $0^{\circ}$ to $60^{\circ} \mathrm{C}$. Figure 1 shows the results obtained at $60^{\circ} \mathrm{C}$, however, very similar data have also been obtained at 22 and $0^{\circ} \mathrm{C}$ as well. Evidently the polymerization is essentially first order in monomer. At lower initiator concentrations ([TMP-OLi] $\sim 10^{-3} \mathrm{M}$ ) induction periods were sometimes noticed. Similar observations have already been described in the anionic polymerization of cyclosiloxanes. ${ }^{8,14-16}$ These induction periods may suggest a somewhat time consuming reorganization of TMP-OLi aggregates upon their addition to the monomer, especially at low initiator concentrations..$^{8,16,17}$ Else, they may be due to protic impurities (moisture?) as observed in the anionic polymerization of $\mathrm{D}_{3}$ initiated by water. ${ }^{14,15}$ In cases of induction periods, kinetic analyses were based on the linear part of the first order plot. ${ }^{14,15}$

Figure 2 shows the effect of initiator concentration on the observed rate constant at 0 , 22 , and $60^{\circ} \mathrm{C}$. The data can be described by

$$
\begin{aligned}
-\frac{\mathrm{d}\left[\mathrm{D}_{3}\right]}{\mathrm{d} t} & =k_{\mathrm{p}(\mathrm{obs})}\left[\mathrm{D}_{3}\right] \\
& =k_{\mathrm{p}(\mathrm{app})}[-\mathrm{OLi}]^{1 / n}\left[\mathrm{D}_{3}\right]
\end{aligned}
$$

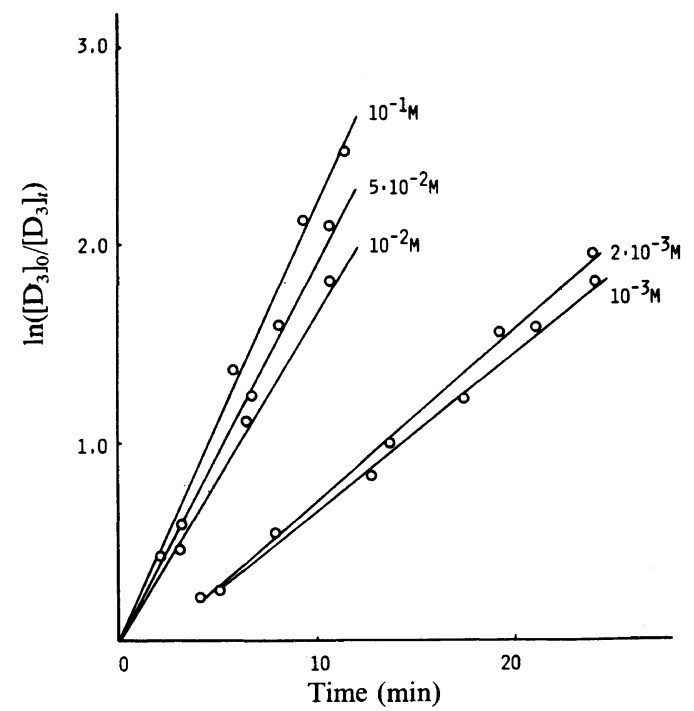

Figure 1. First order plots of $\mathrm{D}_{3}$ conversion at various TMP-OLi concentrations. $\left[\mathrm{D}_{3}\right]=1.0 \mathrm{M} ; \mathrm{THF}, 60^{\circ} \mathrm{C}$.

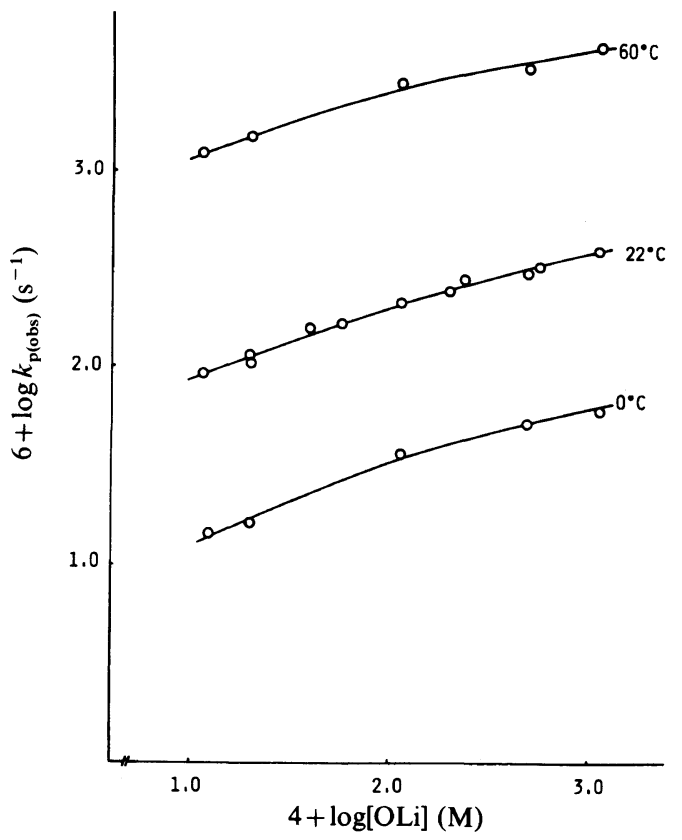

Figure 2. Relationship between observed propagation rate constant $\left(k_{\mathrm{p}(\mathrm{obs})}\right)$ and initiator concentration at different temperatures. $\left[\mathrm{D}_{3}\right]=1.0 \mathrm{M}$; THF.

where $1 / n=0.25-0.33$. Evidently the order changes from $\sim 0.25$ in the $10^{-2}-10^{-1} \mathrm{M}$ [-OLi] range to $\sim 0.33$ in the $10^{-3}-10^{-2} \mathrm{M}$ [-OLi] range, independent of temperature 
from $0^{\circ}$ to $60^{\circ} \mathrm{C}$. We attribute the change in order to a change in the number from 4 to 3 of the active $-\mathrm{SiMe}_{2} \mathrm{OLi}$ centers. Strong aggregates of alcoholates, i.e., carbon analogues of siloxanolates, have been repeatedly investigated. . $^{2,18-21}$

The aggregation tendency of silanolates is expected to be lower than that of alcoholates on account of the $p_{\pi}-d_{\pi}$ participation of the oxygen lone pair of electrons with the adjacent $\mathrm{Si}$ atom. ${ }^{22}$ Indeed the aggregation number of living ethylene oxide ( 4 with $\mathrm{Na}^{\oplus}, 3$ with $\mathrm{K}^{\oplus}$ and $\left.\mathrm{Cs}^{\oplus}\right)^{19}$ was higher than that of $\mathrm{D}_{3}$ (2 with $\mathrm{Na}$ and $\mathrm{K}){ }^{7}$ The lower orders, i.e., higher aggregation numbers, with respect to [-OLi] found in this work are probably due to the stronger aggregation tendency of lithium siloxanolates $-\mathrm{SiMe}_{2} \mathrm{OLi}$ than the other alkali metal siloxanolates $-\mathrm{SiMe}_{2} \mathrm{OM}$ where $\mathrm{M}=\mathrm{Na}$, $\mathrm{K}, \mathrm{Rb}, \mathrm{Cs}^{23}$ The results of our kinetic studies may be rationalized in terms of aggregation equilibria which in turn control the concentration of active propagating siloxanolate end groups. The fractional orders found in the $\mathrm{D}_{3} / \mathrm{TMP}-\mathrm{OLi} / \mathrm{THF}$ system would indicate a strong shift toward aggregates and a relatively small portion of free (non-aggregated) living ends. Further, the high specificity of $\mathrm{D}_{3}$ polymerization in the presence of lithium counterion $v i s-\grave{a}-v i s$ the other alkali metal cations ${ }^{7}$ suggests that the active ends are ion pairs and not free ions:

$$
n \sim m m \mathrm{Me}_{2} \mathrm{SiOLi} \stackrel{K_{n}}{\rightleftharpoons}\left(\operatorname{mm} \mathrm{Me}_{2} \mathrm{SiOLi}\right)_{n}
$$

Free siloxanolates are active propagating centers whereas the bulk of the siloxanolates are dormant, i.e., tied up in aggregates. Thus the reciprocal of the order with respect to the TMP-OLi initiator will reflect the average degree of association, $n$ :

$$
\begin{aligned}
-\frac{\mathrm{d}\left[\mathrm{D}_{3}\right]}{\mathrm{d} t} & =k_{\mathrm{p}}[-\mathrm{OLi}]\left[\mathrm{D}_{3}\right] \\
& =\frac{k_{\mathrm{p}}}{\left(n K_{n}\right)^{1 / n}}[-\mathrm{OLi}]_{0}^{1 / n}\left[\mathrm{D}_{3}\right]
\end{aligned}
$$

$$
k_{\mathrm{p}(\mathrm{app})}=\frac{k_{\mathrm{p}}}{\left(n K_{n}\right)^{1 / n}}
$$

where $n=0.25-0.33$, and $[-\mathrm{OLi}]$ and $[-\mathrm{OLi}]_{0}$ are the unaggregated ("free") siloxanolate and total siloxanolate concentrations, respectively.

The 0.25 order in initiator $\left(10^{-2}-10^{-1} \mathrm{M}\right.$ range) reflects $n=4$, i.e., tetramers whereas the 0.33 order $\left(10^{-3}-10^{-2} \mathrm{M}\right.$ range) indicates $n=3$, i.e., trimers. The external orders indicate average degree of aggregation, for example, the 0.33 order may reflect the presence of dimers and tetramers. The higher order obtained at lower [-OLi] concentrations suggests that dilution shifts the system toward lower aggregates. The concentration effect is not large and dilution by two orders of magnitude decreases the degree of aggregation from four to only three ( $c f$., Figure 2).

Figure 3 shows the effect of temperature on the rate constants from $0^{\circ}$ to $60^{\circ} \mathrm{C}$. Evidently $\Delta H_{\mathrm{app}}^{\neq}$is unaffected by the extent of aggregation in the $10^{-3}-10^{-1} \mathrm{M}$ OLi range. In view that the temperature does not effect the aggregation equilibria from 0 to $60^{\circ} \mathrm{C}$, they must be controlled by entropy factors. We find it rather remarkable that the complicated reorganizations that must occur when the system changes its degree of aggregation from 3 to 4 (association-dissociation, solvation-desolvation) are essentially enthalpy neutral. The kinetic and thermodynamic parameters calculated by the use of eq 1 are compiled in Table I. The activation parameters are essentially the same in the 0 to $60^{\circ} \mathrm{C}$ range for the entire $10^{-3}$ to $10^{-1} \mathrm{M}$ initiator range.

\section{Viscometry}

The purpose of these studies was independently to confirm the conclusions derived from kinetic investigations, particularly those in regard to the degree of aggregation. Viscometric studies were envisioned to provide quantitative information relative to the macroaggregation in the living $\mathrm{D}_{3} / \mathrm{TMP}-\mathrm{OLi} / \mathrm{THF}$ system.

In most systems investigated to date in 
Table I. Kinetic parameters of $\mathrm{D}_{3}$ polymerization calculated from eq 1 $\left([\mathrm{TMP}-\mathrm{OLi}]=10^{-3}-10^{-1} \mathrm{M} ;\left[\mathrm{D}_{3}\right]=0.05-1.0 \mathrm{M} ; \mathrm{THF}, 0-60^{\circ} \mathrm{C}\right)$

\begin{tabular}{|c|c|c|c|c|c|}
\hline [-OLi] range & $k_{\mathrm{p}(\mathrm{app})} \times 10^{4}$ & $1 /$ & $\Delta H_{\mathrm{app}}^{\neq \mathrm{a}}$ & $\Delta S_{\mathrm{app}}^{\neq \mathrm{a}}$ & $\Delta G_{\mathrm{app}}^{\neq \mathrm{a}}$ \\
\hline $\mathbf{M}$ & $1^{3 / n} \mathrm{~mol}^{-1 / n} \mathrm{~s}^{-1}$ & & $\mathrm{kcal} \mathrm{mol}^{-1}$ & cal mol ${ }^{-1} \mathrm{~K}^{-1}$ & $\mathrm{kcal} \mathrm{mol}^{-1}$ \\
\hline $\begin{array}{l}10^{-3}-10^{-2} \\
10^{-2}-10^{-1}\end{array}$ & $\begin{array}{r}6.3 \\
10.4\end{array}$ & $\begin{array}{l}0.23 \pm 0.03 \\
0.36 \pm 0.05\end{array}$ & $12.6 \pm 1.1$ & $-24.1 \pm 2.5$ & $19.7 \pm 1.1$ \\
\hline
\end{tabular}

a Calculated for $22^{\circ} \mathrm{C}$.

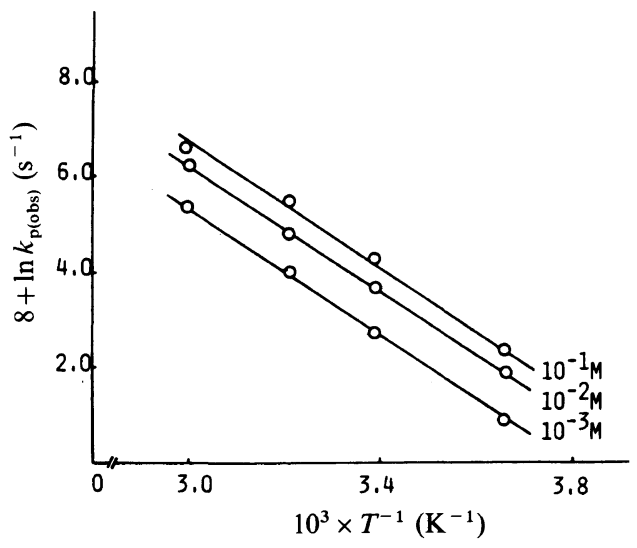

Figure 3. The effect of temperature on the observed propagation rate constant at different TMP-OLi concentrations. $\left[\mathrm{D}_{3}\right]=1.0 \mathrm{M}$; THF.

regard to the degree of aggregation ${ }^{4}$ the relationship between solution viscosity and $\bar{M}_{n}$ had to be known which required sometimes laborious calibration effort and only common linear polymers with degree of aggregation $\sim 2$ gave reliable information. The system under investigation, i.e., a system yielding narrow molecular weight distribution product uncontaminated by products of redistribution processes, is similar to that studies by others ${ }^{24}$ provides a simple universal approach for determining the degrees of aggregation by determining the ratio of viscosities of a living $D_{3}$ polymerizations before and after deactivation ("killing") by chlorosilanes carrying 1, 2, 3, or $4 \mathrm{Cl}-\mathrm{Si}$ groups. Thus, killing a living $\mathrm{D}_{3}$ polymerization with an excess of $\mathrm{Me}_{3} \mathrm{SiCl}$ will destroy the aggregates

$$
\begin{aligned}
& \left(m m \mathrm{Me}_{2} \mathrm{SiOLi}\right)_{n}+n \mathrm{Me}_{3} \mathrm{SiCl} \\
& \longrightarrow n \sim m m \mathrm{Me}_{2} \mathrm{SiO}-\mathrm{SiMe}_{3}+n \mathrm{LiCl}
\end{aligned}
$$

and the relative viscosity of the system

$$
\eta_{\text {sp(rel) }}=\eta_{\text {sp(deactivated) }} / \eta_{\text {sp(living) }}
$$

will decrease if the average degree of aggregation $n$ is higher than unity. In the absence of aggregation (i.e., $n=1$ ) the viscosity of the solution should not change because only the nature of the end groups will change and the molecular weight of the individual macromolecules remains unchanged. Killing a living $\mathrm{D}_{3}$ polymerization with $n=2$ by the introduction of $\mathrm{Me}_{2} \mathrm{SiCl}_{2}$ (i.e., with precisely stoichiometric quantities of $-\mathrm{SiCl}$ functions relative to the $\sim \mathrm{Me}_{2} \mathrm{SiOLi}$ end groups) sould not .change the relative viscosity, i.e., $\eta_{\mathrm{sp}(\mathrm{rel})}=1$. Similarly, and importantly for our particular case where kinetic studies indicated $n=3$ or 4 , the addition of stoichiometric quantities of $\mathrm{MeSiCl}_{3}$ or $\mathrm{SiCl}_{4}$ (or $\mathrm{Cl}_{2} \mathrm{MeSi}-\mathrm{CH}_{2} \mathrm{CH}_{2}-$ SiMeCl${ }_{2}$ ) will yield unity $\eta_{\text {sp(rel) }}$ only if $n$ was in fact 3 or 4 , respectively.

In order to carry out these experiments we had to be sure of the molarities of our systems (i.e., the $\bar{M}_{n}$ s of the living polymers) to calculate exact stoichiometries, we had to be certain that the deactivations went to completion, and the experiments had to be carried out under the exact conditions the kinetic experiments were performed. These requirements have been attained by working under anhydrous conditions under high vacuum and $\mathrm{N}_{2}$ viscometers ( $c f$. ., Experimental) and with frequent sampling as a function of time of both 


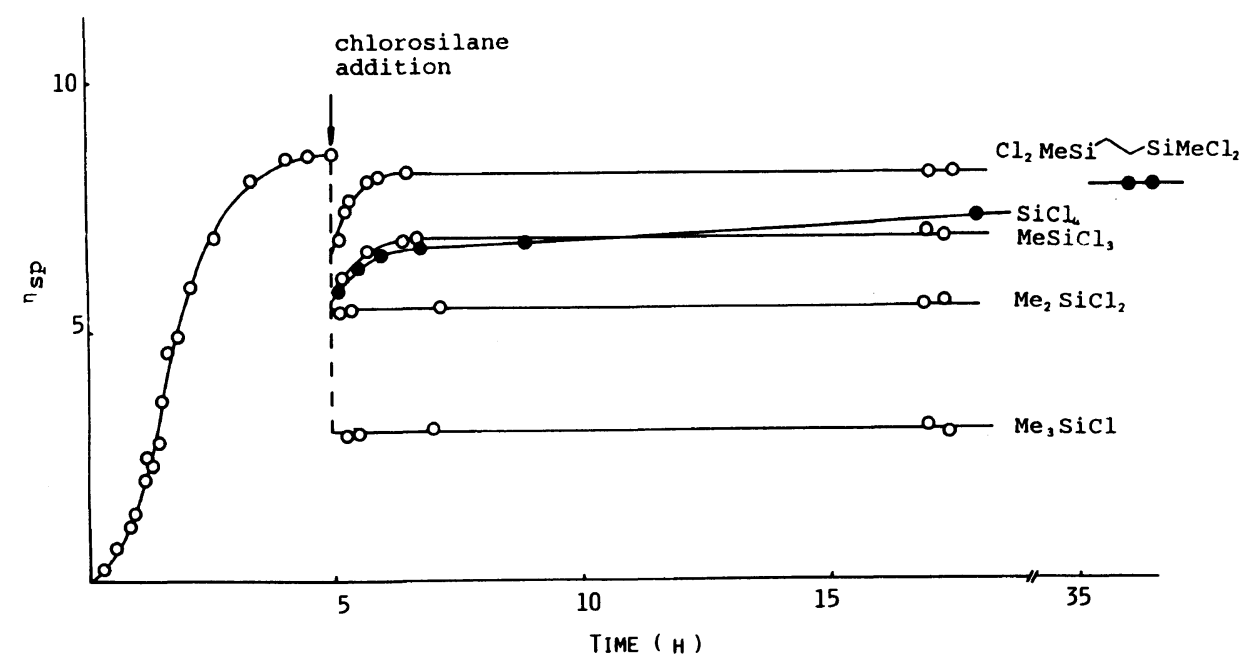

Figure 4. Specific viscosity of $\mathrm{D}_{3}$ polymerization systems versus time before and after addition of different chlorosilanes. $\left[\mathrm{D}_{3}\right]=1.0 \mathrm{M} ;[\mathrm{TMP}-\mathrm{OLi}]=2 \times 10^{-2} \mathrm{M} ; \mathrm{THF}, 22^{\circ} \mathrm{C}$.

the living and deactivated systems to ascertain that constant viscosities have been reached.

Figure 4 shows the results of a representative run and Table II summarizes the data. The viscosity of the living polymerization charge was followed until constant viscosity was reached (i.e., the $\mathrm{D}_{3}$ polymerization reached completion, 5-20 h) at which point the charge was deactivated by the introduction of the proper concentration of various chlorosilanes. Again, the viscosity was followed as a function of time until it reached a constant value $(0.5-40 \mathrm{~h})$.

The rate of deactivation was strongly affected by the particular chlorosilane used. With $\mathrm{Me}_{3} \mathrm{SiCl}$ and $\mathrm{Me}_{2} \mathrm{SiCl}_{2}$ at $[-\mathrm{OLi}]=$ $2 \times 10^{-2} \mathrm{M}$ the reactions went to completion within $0.5 \mathrm{~h}$, with $\mathrm{MeSiCl}_{3} \sim 2 \mathrm{~h}$ were needed, and with $\mathrm{SiCl}_{4}$ the viscosity was still slowly increasing after $35 \mathrm{~h}$. Control experiments carried out in the absence of chlorosilane showed that the effect of redistribution processes on the viscosity was negligible within this time period. Evidently $\sim \mathrm{Me}_{2} \mathrm{SiOLi}$ is able rapidly to react with one or two $\mathrm{Cl}-\mathrm{Si}$ bonds at the same $\mathrm{Si}$ atom at $\sim 10^{-2} \mathrm{M}$ whereas reactions at the third and particularly at the fourth $\mathrm{Cl}-\mathrm{Si}$ bond are much slower (indeed the viscosity kept slowly increasing even after $40 \mathrm{~h}$ with $\mathrm{SiCl}_{4}$ ). Similar phenomena have been reported with the living polystyryl lithium system as well. ${ }^{25,26)}$ This retardation of substitution with an increasing number of $\mathrm{Cls}$ on $\mathrm{Si}$ is most likely due to steric hindrance by the macrosubstituents and/or to reduced diffusion of the $\sim \mathrm{Me}_{2} \mathrm{SiOLi}$ end groups to the $\mathrm{Si}-\mathrm{Cl}$ site. To avoid these effects and to accelerate the deactivation reaction with systems with $n=4$, we have employed $\mathrm{Cl}_{2} \mathrm{MeSi}-$ $\mathrm{CH}_{2} \mathrm{CH}_{2}-\mathrm{SiMeCl}_{2}$. Gratifyingly this tetrafunctional chlorosilane reacted $1-2$ orders of magnitude faster than $\mathrm{SiCl}_{4}$, most likely because the steric restriction to substitution by $\sim \mathrm{Me}_{2} \mathrm{SiOLi}$ around the $\mathrm{Si}$ is much lower.

At lower initiator concentrations $([-\mathrm{OLi}]=$ $10^{-3} \mathrm{M}$ ) extended times had to be used $(\sim 12 \mathrm{~h})$ to ensure complete coupling.

The ratio of viscosities before and after deactivation, $\eta_{\text {sp(rel) }}$, are shown in Table II. The $\mathrm{D}_{3}$ concentrations used were determined by experimental convenience: they were selected to give reasonable viscosities within a reasonably short time $(40-500 \mathrm{~s}$ flow times) in both ranges of TMP-OLi concentrations of 
Table II. Degree of $\sim \mathrm{Me}_{2} \mathrm{SiOLi}$ aggregation from relative viscosities obtained with various chlorosilanes $\left(\mathrm{THF}, 23^{\circ} \mathrm{C}\right)$

\begin{tabular}{|c|c|c|c|c|c|c|c|c|}
\hline \multirow{2}{*}{ Exptl. } & \multirow{2}{*}{$\frac{[\mathrm{TMP}-\mathrm{OLi}] \times 10^{3}}{\mathrm{M}}$} & \multirow{2}{*}{$\frac{\left[\mathrm{D}_{3}\right]}{\mathrm{M}}$} & \multicolumn{5}{|c|}{$\eta_{\mathrm{sp}(\text { rel) })}=\eta_{\mathrm{sp(deactivated)}}{ }^{\mathrm{a}} / \eta_{\mathrm{sp} \text { (living) }} \mathrm{b}$} & \multirow{2}{*}{$\begin{array}{c}\text { Degree of } \\
\text { aggregation }\end{array}$} \\
\hline & & & $\mathrm{Me}_{3} \mathrm{SiCl}$ & $\mathrm{Me}_{2} \mathrm{SiCl}_{2}$ & $\mathrm{MeSiCl}_{3}$ & $\mathrm{SiCl}_{4}$ & $\begin{array}{c}\mathrm{Cl}_{2} \mathrm{MeSi}_{\left(\mathrm{CH}_{2}\right)_{2}} \\
\mathrm{SiMeCl}_{2}\end{array}$ & \\
\hline 1 & 1.14 & 0.50 & 0.74 & & & & & \\
\hline 2 & 2.29 & 0.50 & 0.67 & 0.88 & 1.05 & & 1.45 & $\sim 3$ \\
\hline 3 & 2.29 & 0.50 & & 0.87 & & & 1.38 & \\
\hline 4 & 2.29 & 0.50 & 0.69 & 0.88 & & & & \\
\hline 5 & 4.58 & 0.50 & 0.62 & 0.82 & $\underline{0.98}$ & & & $\sim 3$ \\
\hline 6 & 22.9 & 1.00 & 0.37 & 0.66 & $\overline{0.81}$ & 0.85 & 0.96 & $\sim 4$ \\
\hline 7 & 22.9 & 1.00 & 0.34 & & 0.83 & 0.88 & & \\
\hline 8 & 22.9 & 1.00 & & 0.63 & & $0.93^{\circ}$ & & $\sim 4$ \\
\hline 9 & 57.2 & 1.00 & 0.32 & & 0.78 & & $\underline{0.98}$ & $\sim 4$ \\
\hline
\end{tabular}

${ }^{a} \eta_{\text {sp(deactivated) }}$ determined $12 \mathrm{~h}$ after the chlorosilane addition.

b $\eta_{\text {sp(living) }}$ determined after complete $\mathrm{D}_{3}$ conversion $(5-20 \mathrm{~h})$.

c $\eta_{\text {sp(deactivated) }}$ determined $36 \mathrm{~h}$ after $\mathrm{SiCl}_{4}$ addition.

interest $[\mathrm{TMP}-\mathrm{OLi}]=10^{-3}$ to $10^{-2}$ and $10^{-2}$ to $10^{-1}$ ), i.e., in the ranges where kinetic studies indicated $n=3$ and 4 , respectively.

In the $[\mathrm{TMP}-\mathrm{OLi}]=10^{-3}$ to $10^{-2}$ range (Experiments 1-5, Table II) viscosities before and after deactivation remained unchanged $\left(\eta_{\text {sp(rel) }} \sim 1\right)$ only when $\mathrm{MeSiCl}_{3}$ was used as the killing agent (Experiments 2 and 5). These results are viewed to indicate a degree of aggregation of three $(n=3)$ in this concentration range. As expected, the $\eta_{\text {sp(rel) }}$ values obtained with $\mathrm{Me}_{3} \mathrm{SiCl}$ and $\mathrm{Me}_{2} \mathrm{SiCl}_{2}$ are consistently lower than unity, and the values with $\mathrm{Me}_{3} \mathrm{SiCl}$ are lower than those obtained with $\mathrm{Me}_{2} \mathrm{SiCl}_{2}$. In the same vein, $\eta_{\text {sp(rel) }}$ is higher than unity upon deactivation with $\mathrm{Cl}_{2} \mathrm{MeSi}$ $\mathrm{CH}_{2} \mathrm{CH}_{2}-\mathrm{MeSiCl}_{2}$. Destruction of $n=3 \mathrm{ag}$ gregates with a monofunctional killing agent should obviously give the lowest $\eta_{\text {sp(rel) }}$, whereas the use of stoichiometric quantities of a difunctional killing agent that will yield coupled (linear) polymers should give somewhat higher $\eta_{\text {sp(rel) }}$, but still less than unity. Similarly, deactivation of $n=3$ aggregates with stoichiometric amounts of a tetrafunctional killing agent must yield four arm star polymers with higher than unity $\eta_{\text {sp(rel). }}$. The exact quan- titative interpretation of $\eta_{\mathrm{sp}(\mathrm{rel})} \neq 1$ values is way beyond the scope of these investigations. Similar changes in viscosities have been observed in living ethylene oxide polymerization deactivated by methyl iodide. ${ }^{19}$

In the $[\mathrm{TMP}-\mathrm{OLi}]=10^{-2}$ to $10^{-1}$ range (Experiments 6-9, Table II) where according to kinetic studies $n=4$ aggregates exist, $\eta_{\mathrm{sp} \text { (rel) }}$ was unity only when tetrafunctional killing agents were used. The less than unity $\eta_{\text {sp(rel) }}$ data obtained with $\mathrm{SiCl}_{4}$ in Experiments 6 and 7 are obviously due to incomplete deactivation. As anticipated and similarly to the observations made in the lower TMP-OLi concentration range, the $\eta_{\text {sp(rel) }}$ values are directly proportional to the functionality of the chlorosilane killing agents used. Evidently the degree of aggregation in the [TMP-OLi]$10^{-2}-10^{-1}$ range is four.

\section{CONCLUSIONS}

A combination of kinetic and viscometric studies demonstrate that $D_{3}$ polymerizations in the presence of lithium counterion in THF in the 0 to $60^{\circ} \mathrm{C}$ range are dominated by aggregation phenomena. We propose that 
most of the siloxanolate end groups are "dormant" ion pairs present as aggregates the size of which are determined by reaction parameters, particularly by the living end concentration. Kinetics and viscometry independently indicate a degree of aggregation of 3 and 4 in the $\left[\sim \mathrm{Me}_{2} \mathrm{SiOLi}\right]$ range of $10^{-3}-$ $10^{-2}$ and $10^{-2}-10^{-1} \mathrm{M}$, respectively. The temperature is of much lesser influence in the 0 $60^{\circ}$ range. These results suggest a very strong tendency for aggregation of lithium siloxanolates. The polymerization active living species are visualized as unaggregated ion pairs in equilibrium with the aggregates.

Acknowledgement. Financial help by the Dow Corning Corporation is gratefully acknowledged.

\section{REFERENCES}

1. L. Wilczek, M. K. Mishra, and J. P. Kennedy, in preparation.

2. D. M. French, Rubber Chem. Technol., 42, 71 (1969).

3. M. Morton, L. J. Fetters, J. Inomata, D. C. Rubio, and R. N. Young, Rubber Chem. Technol. 49, 303 (1976).

4. M. Morton, "Anionic Polymerization: Principles and Practice," Academic Press, New York, 1983.

5. M. Szwarc, Adv. Polym. Sci., 49, 1 (1983).

6. S. Bywater, "Anionic Polymerization" in "Encyclopedia of Polymer Science and Engineering," Vol. 2, 2nd ed, Wiley-Interscience, New York, 1985, p 1.

7. P. V. Wright, "Cyclic Siloxanes" in "Ring-Opening Polymerization," Vol. II, K. J. Ivin and T. Saegusa,
Eds., Elsevier, London, 1984, Chapter 14, p 1109.

8. J. Chojnowski and M. Mazurek, Makromol. Chem., 176, 2999 (1975).

9. S. Boileau, Am. Chem. Soc., Symp. Ser., 166, 283 (1981).

10. D. T. Hurd, R. C. Osthoff, and M. L. Corrin, J. Am. Chem. Soc., 76, 249 (1954).

11. W. T. Grubb and R. C. Osthoff, J. Am. Chem. Soc., 77, 1405 (1955).

12. J. E. L. Roovers and S. Bywater, Trans. Faraday Soc., 62, 701 (1966).

13. M. Morton, L. J. Fetters, R. A. Pett, and J. F. Meier, Macromolecules, 3, 327 (1970).

14. C. L. Lee and O. K. Johannson, J. Polym. Sci., Polym. Chem. Ed., 14, 729 (1976).

15. C. L. Lee, O. W. Marko, and O. K. Johannson, J. Polym. Sci., Polym. Chem. Ed., 14, 743 (1976).

16. B. Suryanarayanan, B. W. Peace, and K. G. Mayhan, J. Polym. Sci., Polym. Chem. Ed., 12, 1089 (1974).

17. R. L. Ostrozynski, Polym. Prepr., Am. Chem. Soc., Div. Polym. Chem., 8(1), 474 (1967).

18. J. E. Figueruelo and D. J. Worsfold, Eur. Polym. J., 4, 439 (1968).

19. K. S. Kazanskii, A. A. Solovyanov, and S. G. Entelis, Eur. Polym. J., 7, 1421 (1971).

20. R. N. Young, R. P. Quirk, and L. J. Fetters, $A d v$. Polym. Sci., 56, 1 (1984).

21. V. Halaska, L. Lochman, and D. Lim, Collect. Czech. Chem. Commun., 33, 3245 (1968).

22. R. West and R. H. Baney, J. Am. Chem. Soc., 81, 6145 (1959).

23. J. E. L. Roovers and S. Bywater, Trans. Faraday Soc., 62, 701 (1966).

24. L. J. Fetters and M. Morton, Macromolecules, 7, 552 (1974).

25. S. Bywater, Adv. Polym. Sci., 30, 89 (1979).

26. M. Morton, T. E. Helminiak, S. D. Gadkary, and F. Bueche, J. Polym. Sci., 57, 471 (1962). 